\title{
Prospects for coitally-dependent hormonal contraception: perspectives from women in urban Kenya and Nigeria
}

\author{
Dawn Chin-Quee, ${ }^{1}$ Kelly L'Engle, ${ }^{2}$ Conrad Otterness ${ }^{3}$ *
}

\begin{abstract}
${ }^{1}$ Scientist, Division of Health Services Research, FHI 360, Durham, NC, USA

${ }^{2}$ Scientist, Division of Social and Behavioral Health Sciences, FHI 360, Durham, NC, USA

${ }^{3}$ Research Associate, Division of Health Services Research, FHI 360, Durham, NC, USA

${ }^{*}$ Author is no longer with $\mathrm{FHI}$ 360 , but was lead analyst on the study.
\end{abstract}

\section{Correspondence to} Dr Dawn Chin-Quee, Division of Health Services Research, FHI 360, 2224 E. NC Highway 54, Durham, NC 27713, USA; dchin-quee@fhi360.org

Received 21 May 2013 Revised 7 August 2013 Accepted 15 August 2013 Published Online First

7 October 2013

\section{CrossMark}

To cite: Chin-Quee $D$, L'Engle K, Otterness C. J Fam Plann Reprod Health Care 2014;40:170-176.

\begin{abstract}
Introduction Emergency contraceptive pills (ECPs) were developed and marketed with the emergency aspect firmly in mind, but research and anecdotal evidence indicate that some women use them as a form of regular contraception, spurring efforts in the reproductive health community to explore the development of a coitally-dependent oral contraceptive pill.
\end{abstract}

Methods We asked women of reproductive age in Nairobi, Kenya and Lagos, Nigeria how likely they would be to use a hypothetical pericoital pill and why.

Results Bivariate logistic regressions indicated that women aged 18-35 years, with secondary education or higher, and who had ever used condoms or short-acting methods, were more likely to say that they would use this hypothetical pill. Women who had ever used a family planning method or ECPs were also more likely to say they would use this pill. The likely adopters reported that they would use the pericoital method if it prevented pregnancy with little or no health problems and was convenient and easy to use.

Conclusion The findings suggest that should a safe and effective pericoital hormonal pill become available then a significant number of women would adopt this method.

\section{INTRODUCTION}

Emergency contraception, which can be used in pill form or as an intrauterine device, provides women with the opportunity to reduce their risk of pregnancy after unprotected sex. Emergency contraceptive pills (ECPs) - available as a dedicated product - were developed and marketed with the 'emergency' aspect firmly in mind, and are not recommended for use as an ongoing contraceptive

\section{Key message points}

- Research and anecdotal accounts suggest some women use emergency contraceptive pills (ECPs) as a regular contraceptive method, prompting interest in a pericoital hormonal method.

- Women who have ever used ECPs or any family planning method are more likely than non-users to endorse use of a hypothetical pericoital method.

- A hormonal contraceptive pill that can be taken as needed holds significant appeal for certain women.

method. ${ }^{1}{ }^{2}$ However, there have been calls from reproductive health experts, advocates and contraceptive users for a method like ECPs - a coitally-dependent hormonal method, or 'pericoital' method - that can be recommended for use on a regular basis.

Contraceptors are not only concerned about preventing pregnancy; they also want methods that are easy to obtain and convenient to use. Signs of women's penchant for a pericoital hormonal method came largely out of research examining ECP user characteristics and patterns of use. $^{3-5}$ These studies revealed that women liked the convenience of ECPs (access, ease of use) and often preferred them to other contraceptive methods. Moreover, $10 \%$ of ECP users interviewed at selected pharmacies in Accra, Ghana purchased the product in advance of need; ${ }^{6} 26 \%$ and $80 \%$ of Postinor $2^{\circledR}$ and Norlevo ${ }^{\circledR}$ users, respectively, reported routinely taking both $0.75 \mathrm{mg}$ levonorgestrel (LNG) tablets either before sex or one before and one 
after coitus (unpublished finding). Thus, some women were deliberately ingesting ECPs not postcoitally as prescribed, but in a manner that suited them.

Women are more likely to adopt and use preferred methods of contraception ${ }^{7}$ and to choose methods with qualities identified as important. ${ }^{8}$ Thus, reproductive health experts recognise the value of providing contraceptive methods that women want. Research has demonstrated the safety of repeated use of pre- and postcoital hormonal contraception ${ }^{9}$ and the lack of negative effects of repeated ECP use on sexual and reproductive behaviour. ${ }^{10}$ As a result, there is now impetus for developing a new dedicated pericoital oral contraceptive product that women can take as needed. Indeed, a recent study of an LNG pericoital oral contraceptive pill was designed to assess the efficacy, safety and acceptability of the product, but was halted due to a protracted recruitment process and funding constraints. ${ }^{11}$ Another clinical trial on the effectiveness, safety and feasibility of an on-demand, LNG-based hormonal contraceptive method is currently being conducted. Efforts to determine and address the anticipated issues of regulation, policy, procurement and demand creation, as well as market research to ascertain acceptability of a pericoital hormonal method among men and women, are also underway.

As part of a study in Nairobi, Kenya and Lagos, Nigeria whose main focus was patterns of use among ECP users, we included questions that asked both ECP users and non-users how likely they would be to use on the one hand, or to adopt as a main method on the other, a hypothetical pericoital oral contraceptive pill. Thus, a large cross-section of women answered both questions. Given the common feature of on-demand contraception, the responses from women who were aware of or had ever used ECPs were expected to be particularly instructive.

\section{METHODS}

We intercepted women 18-49 years of age from high-, middle- and low-income neighbourhoods in Nairobi, Kenya and Lagos, Nigeria. We approached women at high-volume shopping venues such as markets and shopping centres in each of these neighbourhoods to obtain as diverse a group of women as possible. All women who consented to be interviewed were asked questions on demographic characteristics (age, marital status and educational attainment), whether they ever used a contraceptive method (contraceptive history), the likelihood of using a hypothetical pericoital method (HPM), and awareness and ever use of dedicated ECP products. Women from whom we obtained data on the likelihood of using an HPM included those who had never used a family planning (FP) method or a dedicated ECP product as well as those who had ever used a contraceptive method. Trained data collectors used smart phones to administer the short interview and to record participant responses.

We asked both questions on the HPM using a fourpoint Likert scale response set (very likely, somewhat likely, somewhat unlikely, very unlikely). The first question asked about the general likelihood of using the hypothetical method: "If there was a pill you could take to prevent pregnancy, but you take it only when you have sex and as often as needed (emphasis added by interviewer), how likely would you be to use it?" No additional information on product characteristics or the effectiveness of this hypothetical method was provided to participants.

The second question asked about the likelihood of the woman adopting the hypothetical pill as her main method of contraception: "How likely would you be to adopt this type of pill as your main method of preventing pregnancy?" In order to simplify the analysis and presentation of results, responses to both questions were dichotomised to indicate likely (very + somewhat) or unlikely (very+somewhat) to use/adopt the hypothetical method.

We performed bivariate logistic regression analysis to assess the associations among demographic characteristics, contraceptive history and likelihood of generally using or adopting the HPM as a main contraceptive method.

We also asked an open-ended question as a follow-up to the item on adoption: "Why would you adopt/not adopt this type of pill as your main contraceptive method?" The open-ended responses were primarily short sentences or phrases. The first author coded all open-ended responses, recording and maintaining emerging themes in an Excel spreadsheet. A single response could be given more than one code if multiple themes were articulated. The analyst (the third author) then verified the coding, using the coded themes in the Excel file. In cases of disagreement, both coders discussed and agreed on the best code(s) for a particular response. In instances where the open-ended response did not match the linked Likert response (i.e. the interviewer recorded that the woman was likely or unlikely to adopt the pill, but the open-ended response indicated the opposite), we considered responses to both questions uninterpretable. This resulted in a total of $4 \%$ uninterpretable responses for Lagos and 1\% for Nairobi, which were excluded from analyses.

The full study of ECP use patterns in urban Kenya and Nigeria, of which the described procedure is a part, was approved by FHI 360's Protection of Human Subjects Committee (PHSC), Kenya's Medical Research Institute (KEMRI) and Nigeria's National Health Research Ethics Committee (NHREC).

\section{RESULTS}

In total, 9581 women were intercepted, 2359 were deemed ineligible and 1060 refused to be interviewed. 
Thus, 6162 women participated with 4431 (72\%) reporting awareness of ECPs and 1073 (17\%) having ever used them. Figure 1 illustrates the distribution of women in Nairobi and Lagos of whom 67\% had ever used an FP method.

\section{Demographic characteristics}

The mean age of women we interviewed in Lagos was 30 years and 28 years in Nairobi (data not shown). Most women who ever used FP or ECPs fell in the 2534 years age range in both cities. In general, women in Lagos who reported ever having used an FP method or ever having used ECPs were older than their counterparts in Nairobi. Further, a greater proportion of married than single women in Lagos had ever used ECPs, while in Nairobi we saw the reverse, with a smaller proportion of married women overall. Higher levels of education were reported by Nigerian women, as more women with post-secondary degrees were interviewed in Lagos compared to Nairobi (Table 1).

\section{Contraceptive history (ever use of individual methods)}

Our samples' contraceptive use indicated that a greater proportion of women in Nairobi $(76 \%)$ than in Lagos (59\%) had ever used an FP method. Condoms were the most common method ever used by women in both Nairobi (44\%) and Lagos (51\%). In Nairobi, condom use was followed in prevalence by use of injectables (43\%), daily birth control pills (39\%) and natural family planning (NFP; 26\%). In Lagos, condom use was followed by use of NFP (29\%), withdrawal (28\%), daily pills (17\%) and injectables (13\%).

\section{Likelihood of pericoital method use}

The results of bivariate logistic regressions for both likelihood questions are shown in Table 2.

The findings for age are consistent across the two questions in that women aged between 18 and 34 years were significantly more likely than those aged 35-49 years to report likely use or wholesale adoption of the HPM. Results for education consistently showed that for both likelihood scenarios, women from Lagos with post-secondary or higher and women from Nairobi with secondary education were significantly more likely to endorse the HPM than women with primary school education or less. Women from Lagos who were separated, divorced or widowed were significantly less likely than single women to sanction the hypothetical pill.

Consistency is also seen across both countries with regard to FP history, such that women who had ever used ECPs or another FP method were significantly more likely than women who had never used any form of FP to endorse the hypothetical method. The association was much stronger among our Nigerian than Kenyan sample and among those who had ever used ECPs versus ever used any other FP method. Examination of ever use of individual methods indicated that women from Nairobi who had ever used condoms and short-acting methods (pills and injectables) were significantly more likely to use the HPM than their counterparts who had never used those methods. Ever users of pills and injectables from Lagos were also significantly more likely to use the HPM than never users of shortacting methods. For long-acting reversible methods, NFP and traditional methods, both groups of women who had ever used those methods were significantly less likely than those who never used them to say that they would use the hypothetical method.

Reasons for likelihood to adopt or not adopt the HPM were classified by FP history (Table 3). In both Lagos and Nairobi, the most common reason for adopting the hypothetical method was the belief that such a method would prevent pregnancy with few or no side effects.

Another noteworthy reason for adoption was potential convenience and ease of use of the pericoital method.

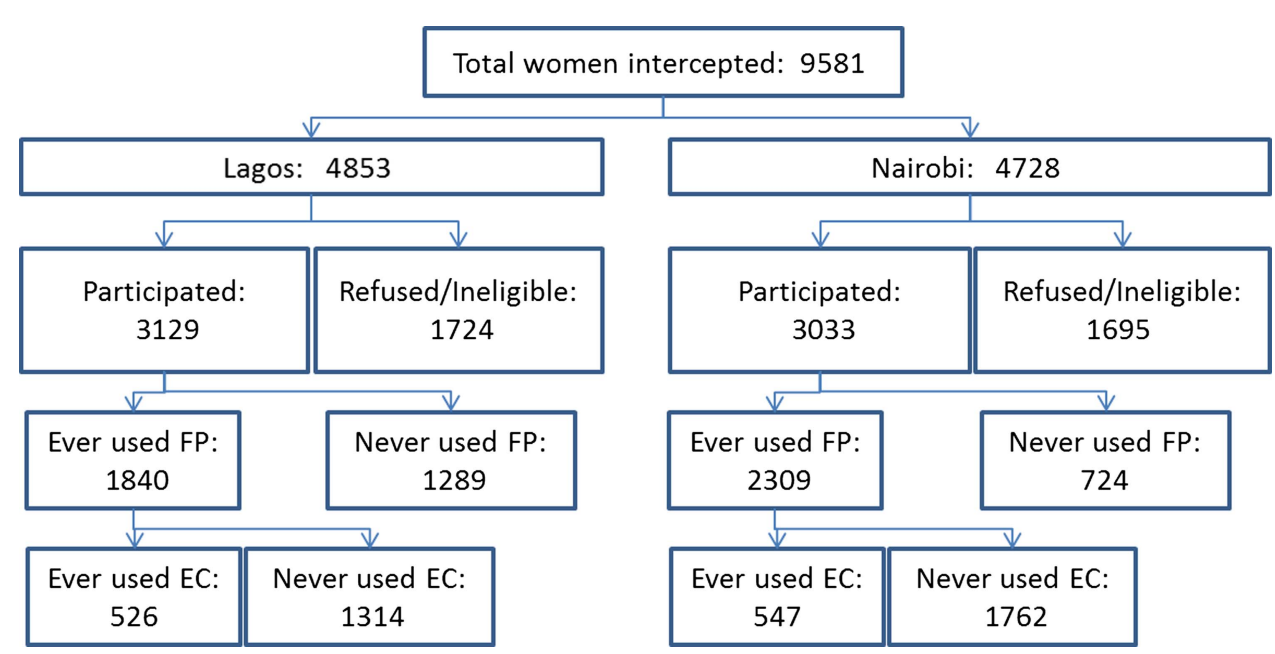

Figure 1 Flowchart of study recruitment and participation in Lagos and Nairobi. EC, emergency contraception; FP, family planning. 
Table 1 Background characteristics of study participants in Lagos and Nairobi by contraceptive history

\begin{tabular}{|c|c|c|c|c|c|c|}
\hline \multirow[b]{3}{*}{ Demographic characteristic } & \multicolumn{3}{|c|}{ Lagos $(n=3129)$} & \multicolumn{3}{|c|}{ Nairobi $(n=3033)$} \\
\hline & \multicolumn{2}{|c|}{ Ever used FP $(n=1840)$} & \multirow[b]{2}{*}{$\begin{array}{l}\text { Never used } \\
\text { FP } \\
(n=1289)\end{array}$} & \multicolumn{2}{|c|}{ Ever used FP $(n=2309)$} & \multirow[b]{2}{*}{$\begin{array}{l}\text { Never used } \\
\text { FP } \\
(n=724)\end{array}$} \\
\hline & $\begin{array}{l}\text { Ever used } \\
\text { ECPs } \\
(n=526)\end{array}$ & $\begin{array}{l}\text { Never used } \\
\text { ECPs } \\
(n=1314)\end{array}$ & & $\begin{array}{l}\text { Ever used } \\
\text { ECPs } \\
(n=547)\end{array}$ & $\begin{array}{l}\text { Never used } \\
\text { ECPs } \\
(n=1762)\end{array}$ & \\
\hline Age: mean (years) & 31.6 & 32.4 & 27.7 & 27.4 & 30.6 & 24.2 \\
\hline \multicolumn{7}{|l|}{ Age distribution in years (\%) } \\
\hline $18-24$ & 17 & 16 & 40 & 40 & 25 & 65 \\
\hline $25-34$ & 48 & 44 & 38 & 44 & 44 & 26 \\
\hline $35-44$ & 28 & 30 & 16 & 14 & 24 & 8 \\
\hline $45-49$ & 7 & 9 & 5 & 2 & 6 & 1 \\
\hline \multicolumn{7}{|l|}{ Marital status (\%) } \\
\hline Married & 59 & 62 & 43 & 36 & 59 & 16 \\
\hline Single & 38 & 33 & 54 & 58 & 30 & 81 \\
\hline Separated/divorced/widowed & 3 & 5 & 3 & 6 & 10 & 4 \\
\hline No response & $<1$ & 1 & $<1$ & 0 & $<1$ & 0 \\
\hline \multicolumn{7}{|l|}{ Educational attainment (\%) } \\
\hline Primary or less & 3 & 4 & 8 & 12 & 38 & 26 \\
\hline Secondary & 40 & 47 & 58 & 44 & 39 & 48 \\
\hline College or higher & 56 & 47 & 33 & 44 & 23 & 25 \\
\hline No response & 1 & 1 & 1 & 0 & $<1$ & 1 \\
\hline
\end{tabular}

The inverse pattern was evident for those who would not adopt the pericoital method.

Women in both cities who had never used ECPs were more likely to state that they would not adopt the pericoital method because they believed it would cause problems with health and reproduction.

Women were also less in favour of a new pericoital method if they were already using contraception, didn't consider the pericoital pill an FP method, or didn't have the interest or desire to take drugs.

Reasons for not adopting the hypothetical method were also expressed in the form of sociocultural or religious proscriptions.

In some cases, the same reasons were given by women whether they reported being likely or unlikely to adopt the pericoital method, such as the need for more information or not having sex regularly. These dual-purpose explanations were mentioned by $5 \%$ or fewer women and were not combined with reasons distinctly for or against adoption of the pericoital method.

The pericoital method's potential effect on condom use did not appear to loom large in the minds of women. Fewer than $2 \%$ of respondents spontaneously mentioned that the pericoital method would decrease the need for condoms or, alternatively, that it would be an inferior replacement for a barrier method that also protects against STIs and HIV.

\section{DISCUSSION}

These data show that there is definite interest in an on-demand oral contraceptive pill among urban women in Nigeria and Kenya. Potential acceptance and use vary by contraceptive history, helping to define where promotional efforts for introduction of a new pericoital method can be focused. The majority of women interviewed in Lagos and Nairobi had never used ECPs, and as the findings demonstrated, might have less affinity to the hypothetical method than the $17 \%$ of our urban samples who had ever used ECPs. By specifically examining responses from women who had ever used an FP method and, more importantly, by those who had ever used a dedicated ECP product, the implications for segmenting these women become very clear. From a market research perspective, targeting women who have ever used ECPs, condoms and short-acting methods would be the 'low-hanging fruit' in demand creation efforts for the pericoital product. Moreover, it is not surprising that women who already use on-demand (ECP, condom) or short-acting methods (pills, injectables) would be more likely to use a pericoital pill, as it might hold less appeal for those who have used longer-term or prefer natural or traditional methods. It remains noteworthy, however, that a substantive minority of women who never used FP would consider using the HPM as well.

Comparisons between Lagos and Nairobi also illustrate how special considerations and approaches might be required to introduce this product in different settings. For example, contraceptive prevalence rates (CPR) and the method mix might influence acceptance of the pericoital product. In Nigeria where the CPR and short-term hormonal method use are both 
Table 2 Bivariate logistic regressions of likelihood to use or adopt hypothetical pericoital method as main contraceptive method

\begin{tabular}{|c|c|c|c|c|}
\hline \multirow[b]{2}{*}{$\begin{array}{l}\text { Demographic characteristics and } \\
\text { contraceptive history }\end{array}$} & \multicolumn{2}{|c|}{ Likely to use } & \multicolumn{2}{|c|}{ Likely to adopt as main method } \\
\hline & $\begin{array}{l}\text { Lagos } \\
(n=3129) \\
\text { OR }\end{array}$ & $\begin{array}{l}\text { Nairobi } \\
(n=3033) \\
\text { OR }\end{array}$ & $\begin{array}{l}\text { Lagos } \\
(n=3129) \\
\text { OR }\end{array}$ & $\begin{array}{l}\text { Nairobi } \\
(n=3033) \\
\text { OR }\end{array}$ \\
\hline \multicolumn{5}{|l|}{ Age (years) } \\
\hline $18-34$ & $1.6^{* *}$ & $1.6^{* *}$ & $1.5^{* *}$ & $1.5^{* *}$ \\
\hline 35-49 (Ref) & - & - & - & - \\
\hline \multicolumn{5}{|l|}{ Marital status } \\
\hline Married & 1.1 & 1.1 & 1.1 & 1.1 \\
\hline Separated/divorced/widowed & $0.5^{* *}$ & 0.8 & $0.5^{* *}$ & 0.9 \\
\hline Single (Ref) & - & - & - & - \\
\hline \multicolumn{5}{|l|}{ Educational attainment } \\
\hline College or higher & $1.9^{* *}$ & 1.1 & $1.5^{*}$ & 1.1 \\
\hline Secondary & 1.5 & $1.2^{* *}$ & 1.3 & $1.3^{* *}$ \\
\hline Primary or less (Ref) & - & - & - & - \\
\hline \multicolumn{5}{|l|}{ FP history } \\
\hline Ever used ECP & $14.0^{* *}$ & $7.3^{* *}$ & $13.0^{* *}$ & $6.9^{* *}$ \\
\hline Ever used FP, but not ECPs & $1.8^{* *}$ & $1.9^{* *}$ & $1.7^{*}$ & $2.2^{* *}$ \\
\hline Never used any FP (Ref) & - & - & - & - \\
\hline \multicolumn{5}{|l|}{ Contraceptive use } \\
\hline Condoms & 1.3 & $1.5^{* *}$ & 1.2 & $1.5^{* *}$ \\
\hline Short-acting methods $\ddagger$ & $1.6^{* *}$ & $1.2^{*}$ & $1.6^{* *}$ & $1.3^{* *}$ \\
\hline Long-acting reversible methods§ & $0.3^{* *}$ & $0.5^{* *}$ & $0.3^{* *}$ & $0.5^{* *}$ \\
\hline Natural and traditional FP methods $\uparrow$ & $0.5^{* *}$ & 1.1 & $0.5^{* *}$ & 1.2 \\
\hline
\end{tabular}

${ }^{*} p<0.05 ;{ }^{* *} p<0.01$.

tReference group for these categories are never having used this method.

\#Short-acting methods include: oral contraceptive pills, injectables.

$\S$ Long-acting reversible methods include: intrauterine device and implants.

INatural and traditional FP methods include: withdrawal, traditional methods, other (not otherwise specified).

$E C P$, emergency contraceptive pill; FP, family planning; OR, odds ratio; Ref, reference.

low, the pericoital method may find a ready niche, even among married women as we found in our sample. In Kenya, the greater overall use of effective contraceptives might require a more nuanced approach in introducing the pericoital method, while making a positive contribution to the CPR and avoiding method substitution. More research is recommended to determine how a new pericoital method would be adopted in settings that vary by CPR and method mix.

Women's reasons for adopting the HPM as a main method provide valuable insights into characteristics of a new contraceptive product that would be appealing to women of reproductive age. As others have found, ${ }^{12-15}$ women in our study frequently referred to negative effects of contraception, including side effects, impact on future fertility and long-term health - and without any suggestion of adverse or harmful effects from the interviewer. Thus, a new method that was viewed as effectively preventing pregnancy and having little impact on women's health or reproductive capacity would likely be welcomed. Many women also cited the convenience of direct access and ease of use as important factors for acceptance and use of this new pericoital method. Our data also highlight that cultural norms and personal beliefs about hormonal contraception and FP in general remain substantive reasons for non-use of modern contraception. ${ }^{16}{ }^{17}$ Whether an on-demand pill helps to overcome some of these barriers to contraceptive use warrants further investigation.

Substitution of condoms is a key concern for many, and a pericoital oral contraceptive pill that does not protect against STIs and HIV is likely to come under attack. However, the new product would be no different from many other effective methods of contraception that also do not confer protection. Moreover, very few women mentioned either the appeal or the fear of abandoning condoms for this other coitallydependent method. Thus, for these women, other characteristics including effectiveness, convenience, affordability, lack of side effects, and inherent safety of the hypothetical method were more salient than concerns about STI transmission. In a USA study conducted with women seeking abortions, the features of a contraceptive method they deemed most important were effectiveness, lack of side effects and affordability - a noteworthy overlapping of desired features 
Table 3 Reasons why women would or would not adopt a pericoital method as a main method by women who had ever used emergency contraceptive pills and family planning in Lagos and Nairobi

\begin{tabular}{|c|c|c|c|c|c|c|}
\hline \multirow[b]{3}{*}{ Reason given* } & \multicolumn{3}{|c|}{ Lagos $(n=3001)$} & \multicolumn{3}{|c|}{ Nairobi $(n=2995)$} \\
\hline & \multicolumn{2}{|c|}{ Ever used FP $(n=1747)$} & \multirow[b]{2}{*}{$\begin{array}{l}\text { Never used } \\
\text { FP } \\
(n=1254) \\
\%\end{array}$} & \multicolumn{2}{|c|}{ Ever used FP $(n=2278)$} & \multirow[b]{2}{*}{$\begin{array}{l}\text { Never used } \\
\text { FP } \\
(n=717) \\
\%\end{array}$} \\
\hline & $\begin{array}{l}\text { Ever used } \\
\text { ECPs } \\
(n=501) \\
\%\end{array}$ & $\begin{array}{l}\text { Never used } \\
\text { ECPs } \\
(n=1246) \\
\%\end{array}$ & & $\begin{array}{l}\text { Ever used } \\
\text { ECPs } \\
(n=534) \\
\%\end{array}$ & $\begin{array}{l}\text { Never used } \\
\text { ECPs } \\
(n=1744) \\
\%\end{array}$ & \\
\hline \multicolumn{7}{|l|}{ Why would use pericoital method } \\
\hline Pregnancy prevention with little or no problems & 61 & 25 & 19 & 23 & 14 & 11 \\
\hline Ease/convenience of pericoital method & 11 & 3 & 1 & 29 & 15 & 5 \\
\hline Better than other methods, has non-contraceptive benefits & 4 & 1 & $<1$ & 5 & 4 & 2 \\
\hline $\begin{array}{l}\text { General, unspecified reasons for using/switching to } \\
\text { pericoital method }\end{array}$ & 4 & 1 & $<1$ & 3 & 4 & 4 \\
\hline Eliminates need for condoms & 1 & $<1$ & 0 & 1 & $<1$ & $<1$ \\
\hline Marital status does not affect use & 0 & $<1$ & 0 & 2 & $<1$ & $<1$ \\
\hline \multicolumn{7}{|l|}{ Why would not use pericoital method } \\
\hline Causes problems with health and reproduction & 10 & 42 & 36 & 15 & 23 & 27 \\
\hline $\begin{array}{l}\text { Already using method/not interested in FP/pills/drugs; } \\
\text { pericoital not considered FP }\end{array}$ & 6 & 21 & 20 & 10 & 18 & 7 \\
\hline No guarantee of effectiveness, ease of use, convenience & 1 & 2 & 1 & 5 & 7 & 2 \\
\hline $\begin{array}{l}\text { Sociocultural, marital and/or biological proscriptions against } \\
\text { pericoital use }\end{array}$ & 2 & 4 & 11 & 3 & 7 & 20 \\
\hline $\begin{array}{l}\text { General or unspecified reasons for not using pericoital } \\
\text { method }\end{array}$ & 1 & 2 & 5 & 1 & 3 & 4 \\
\hline Condoms better than pericoital & 0 & 1 & 1 & 1 & 1 & 1 \\
\hline Other & 7 & 5 & 8 & 8 & 9 & 25 \\
\hline No response & 1 & $<1$ & 2 & 2 & 2 & 2 \\
\hline
\end{tabular}

${ }^{*}$ Totals do not add to $100 \%$ because multiple responses possible.

tOther includes the dual-purpose reasons that women used to explain both why they would or would not adopt the pericoital method as a main method. $E C P$, emergency contraceptive pill; $F P$, family planning.

with our African cohort. Indeed, the study's authors noted that an over-the-counter pericoital pill would have $68 \%$ of these desired features. ${ }^{18}$

\section{Limitations of the study}

Although we recruited a diverse group of women, the samples were not representative of the cities' populations. Thus, the associations we found between respondents' characteristics and likelihood to use or fully adopt the pericoital pill may be affected by the samples' limitations.

We cannot confidently state that women did not confuse the HPM with ECPs, but only 1\% or fewer (Lagos and Nairobi, respectively) of our coded responses to the open-ended item suggested that possibility. The one feature that distinguishes ECPs from the HPM (in our description to participants) is not being able to use it as often as one likes, and we asked our ever ECP users if they agreed that a woman should be able to take ECPs as many times as she needs to. In Nairobi, over 70\% of our ECP ever users who would use the pericoital method disagreed that women should take ECPs as many times as needed, suggesting that they recognised the difference between the two methods. In Lagos, where ever ECP users were much more likely than Nairobians to use and adopt the pericoital method as a main method, only $39 \%$ disagreed that women should use ECPs as many times as needed. Thus, it is not as clear if women from Lagos understood the difference between ECPs and the hypothetical method or if it merely supports the finding of their greater affinity for ECPs and the HPM. Gathering information on a product that does not yet exist can be challenging, and for future market research in which ECPs can serve simultaneously as point of reference for a new pericoital product as well as a point of confusion, the challenge will be considerable.

Our comparisons between ever and never users of ECPs was limited to examination of ever users of contraceptives, which did not provide us with information on the current methods used by these women. Therefore, we were unable to determine dual use of ECPs with other methods. Nevertheless, we obtained a valuable snapshot of contraceptive methods ever used by women in these urban settings. Research that examines both choice of methods and their use over time would provide further insight into the role a new pericoital method could play in the method mix. 


\section{CONCLUSIONS}

The study findings showed that a new oral contraceptive pill that can be taken on demand has significant appeal to a substantial segment of women of reproductive age. Moreover, the results contribute to and provide initial guidance to the international global health community for developing market research strategies to introduce a new pericoital hormonal method. Given these positive findings, development of this new product should proceed, keeping in mind that differences in geography, culture, contraceptive history and prevalence will influence adoption.

Acknowledgements The authors would like to thank Dr John Stanback, Dr Vera Halpern and Ms Elizabeth Westley for their helpful comments on earlier drafts of this article.

Funding The research upon which this article is based was funded by the International Consortium for Emergency Contraception (ICEC) through Family Care International.

\section{Competing interests None.}

Ethics approval Protection of Human Subjects Committee (PHSC at FHI 360), Kenya Medical Research Institute (KEMRI) and National Health Research Ethics Committee (NHREC in Nigeria).

Provenance and peer review Not commissioned; externally peer reviewed.

\section{REFERENCES}

1 World Health Organization (WHO). Emergency Contraception (Fact sheet No. 244). Geneva, Switzerland: WHO, July 2012.

2 International Consortium for Emergency Contraception (ICEC), International Federation of Gynecology and Obstetrics (FIGO). Emergency Contraceptive Pills: Medical and Service Delivery Guidelines (3rd edn). New York, NY: ICEC, 2012.

3 Chin-Quee DS, Wedderburn M, Otterness C, et al. Bridging emergency contraceptive pill users to regular contraception: results from a randomized trial in Jamaica. Contraception 2010;81:133-139.

4 L'Engle KL, Hinson L, Chin-Quee D. "I love my ECPs": challenges to bridging emergency contraceptive users to more effective contraceptive methods in Ghana. J Fam Plann Reprod Health Care 2011;37:146-151.
5 Keesbury J, Morgan G, Owino B. Is repeat use of emergency contraception common among pharmacy clients? Evidence from Kenya. Contraception 2011;83:346-351.

6 Chin-Quee D, Hinson L, L'Engle KL, et al. Bridge over troubled waters: considerations in transitioning emergency contraceptive users to hormonal methods. Contraception 2012;85:363-368.

7 Pariani S, Heer DM, Van Arsdol MD Jr. Does choice make a difference to contraceptive use? Evidence from east Java. Stud Fam Plann 1991;22:384-390.

8 Rosales C, Mansour D, Cox MA. Does current contraceptive choice correspond with user satisfaction? J Obstet Gynaecol 2012;32:166-172.

9 Halpern V, Raymond EG, Lopez LM. Repeated use of pre- and postcoital hormonal contraception for prevention of pregnancy. Cochrane Database Syst Rev 2010;1:CD007595.

10 Polis CB, Schaffer K, Blanchard K, et al. Advance provision of emergency contraception for pregnancy prevention: a meta-analysis. Obstet Gynecol 2007;110:1379-1388.

11 Lendvay A, Taylor D, Halpern V, et al. A prospective, open-label, single-arm study to evaluate efficacy, safety and acceptability of pericoital oral contraception with levonorgestrel. Contraception 2012;86:313.

12 Ali M, Cleland J. Contraceptive discontinuation in six developing countries: a cause-specific analysis. Int Fam Plann Perspect 1995;21:92-97.

13 Hubacher D, Goco N, Gonzalez B, et al. Factors affecting continuation rates of DMPA. Contraception 1999;60:345-351.

14 Tolley E, Loza S, Kafafi L, et al. The impact of menstrual side effects on contraceptive discontinuation: findings from a longitudinal study in Cairo, Egypt. Int Fam Plann Perspect $2005 ; 31: 15-23$.

15 Lei ZW, Wu SC, Garceau RJ, et al. Effect of pretreatment counseling on discontinuation rates in Chinese women given depo-medroxyprogesterone acetate for contraception. Contraception 1996;53:357-361.

16 Campbell M, Sahin-Hodoglugil NN, Potts M. Barriers to fertility regulation: a review of the literature. Stud Fam Plann 2006;37:87-98.

17 Nagase T, Kunii O, Wakai S, et al. Obstacles to modern contraceptive use among married women in southern urban Maldives. Contraception 2003;68:125-134.

18 Lessard LN, Karasek D, Ma S, et al. Contraceptive features preferred by women at high risk of unintended pregnancy. Perspect Sex Reprod Health 2012;44:194-200. 